\title{
Reconstructive aortic valve surgery in the elderly: Techniques and outcomes
}

\author{
Paul P. Urbanski, MD, PhD, Atanas Jankulovski, MD, Kiril Doldurov, MD, Xiaochun Zhan, MD, \\ Ayman Sodah, MD, Michael Zacher, MD, and Anno Diegeler, MD, PhD
}

\section{ABSTRACT}

Objectives: The aim of the study was to evaluate operative techniques and longterm results after aortic valve or root repair in patients aged 75 years or more.

Methods: Between November 2002 and January 2016, a total of 815 patients underwent aortic valve or root repair. Among them were 100 patients aged 75 years or more (mean, $78 \pm 3$; range, $75-88$ years), including 17 patients operated on an emergency basis because of acute aortic dissection. None/trivial, mild, moderate, and severe insufficiency grades were presented in 9, 23, 27, and 41 patients, respectively. The surgery comprised root repair, cusp repair, and a combination of both in 45, 16, and 39 patients, respectively.

Results: Early (30-day) mortality and the rate of permanent neurologic deficit were $2 \%$ for each. The follow-up was $99 \%$ complete, resulting in 427 patient/ years. During the follow-up period (mean duration, $4.3 \pm 3.2$; range, 0.02 11.1 years), only 1 patient developed a relevant aortic insufficiency and required aortic valve reoperation. There were 24 late deaths, which occurred on average $50.0 \pm 40.6$ months (range, 2.4-135.0) after surgery at the average patient age of $82 \pm 5$ years (range, 75-90). Estimated survival at 5 and 8 years was $76.4 \% \pm 5.1 \%$ and $71.3 \% \pm 5.9 \%$, respectively, and was similar to those of the sex- and age-matched general population.

Conclusions: Reconstructive aortic valve surgery is a suitable and justifiable surgical option in selected elderly patients undergoing operation by surgeons with considerable experience in this kind of surgery. It offers low cardiac and valverelated mortality and morbidity, leading to life expectancy applicable to the patients' ages. (J Thorac Cardiovasc Surg 2018;155:1414-20)

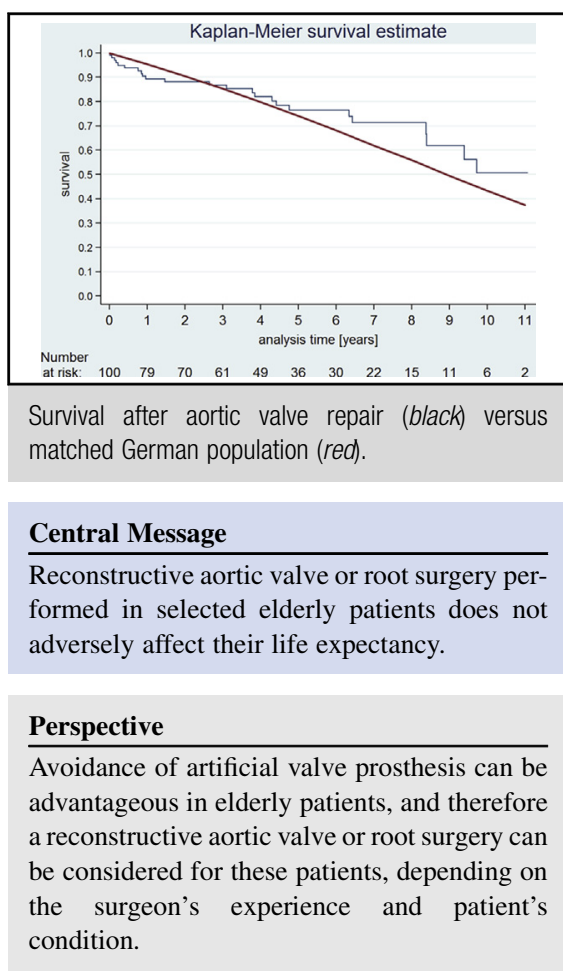

See Editorial Commentary page 1421.
Valve replacement became the method of choice in the surgical treatment of aortic valve defects because the operative techniques are reproducible and the surgical results are easily predictable, even if they strongly depend on demographic and pathologic specifications. ${ }^{1,2}$ This is especially true regarding elderly patients in whom not only their advanced age but also, most important, their accompanying comorbidities clearly affect a perioperative risk, and therefore, the fastest and safest possible procedures are generally recommended. ${ }^{1-5}$ Yet, we believe

From the Cardiovascular Clinic Bad Neustadt, Bad Neustadt, Germany.

Received for publication June 8, 2017; revisions received Nov 2, 2017; accepted for publication Nov 17, 2017; available ahead of print Jan 17, 2018.

Address for reprints: Paul P. Urbanski, MD, PhD, Herz- und Gefaess-Klinik, Salzburger Leite 1, Bad Neustadt 97616, Germany (E-mail: p.urbanski@ herzchirurgie.de). 0022-5223/\$36.00

Copyright (c) 2017 by The American Association for Thoracic Surgery

https://doi.org/10.1016/j.jtcvs.2017.11.096 that elderly patients with suitable pathologic and clinical conditions can also profit from the advantages of valvesparing albeit more complex aortic repair techniques, as has been demonstrated for the young. ${ }^{6,7}$ The aim of the study was to evaluate operative and midterm results after aortic valve or root repair in patients aged 75 years or more.

\section{PATIENTS AND METHODS}

Between November 2002 and January 2016, a total of 815 patients underwent aortic valve or root repair, excluding the repairs of stenotic valves and supracoronary ascending aorta replacements with isolated sinotubularjunction narrowing. Among them were 100 patients aged 75 years or more

- Scanning this $\mathrm{QR}$ code will take you to a supplemental video for the article. 


\section{Abbreviations and Acronyms \\ TEE $=$ transesophageal echocardiography \\ $\mathrm{VSRR}=$ valve-sparing root repair}

(mean, $78 \pm 3$; range, 75-88 years), including 17 patients undergoing operation on an emergency basis because of acute aortic dissection. Aortic diagnostics were based on computed tomography angiography in all but 11 patients, in whom an aortic pathology could definitely be confirmed or ruled out by echocardiography and heart catheterization. None/trivial, mild, moderate, and severe insufficiency grades (defined in accordance to recommendations of the European Association of Echocardiography ${ }^{8}$ ) were presented in 9, 23, 27, and 41 patients, respectively. The aortic valve was tricuspid in all but 2 patients.

The average aortic annulus and ascending aorta diameters were $25.0 \pm 2.6 \mathrm{~mm}$ and $57.1 \pm 9.2 \mathrm{~mm}$, respectively. The detailed patient characteristics are shown in Table 1.

\section{Surgical Technique}

During surgery, transesophageal echocardiography was performed to assess the anatomy and function of the aortic root and valve. The surgery comprised root repair, cusp repair, and a combination of both in 45,16 , and 39 patients, respectively. Aortic root repair using isolated sinus repair was performed in 84 patients. Replacement of 1,2, or 3 sinuses of Valsalva was performed in 29,40, and 15 patients, respectively. The average diameter of the aortic vascular prosthesis used for the root repair was $26.6 \pm 2.5 \mathrm{~mm}$ (range, $22-34 \mathrm{~mm}$ ). Aortic root remodeling with restoration of the individual aortic root anatomy using isolated sinus repair performed on the basis of well-reproducible measurement of the aortic annulus has been described. ${ }^{9-11}$ In short, the proper aortic graft size was chosen by measuring the aortic annulus with a valve sizer and defined as the same size as the biggest sizer that could pass through the aortic valve. Because this passing is not possible in bicuspid valves or in pronounced septal hypertrophy, the sizer was only placed on the valve, and the appropriate size was judged visually. The tube with the same diameter as the aortic annulus or slightly bigger (1-2 mm) was chosen. The pathologic sinuses of Valsalva, especially those with dissected aortic wall were excised, leaving a minimal rim of aortic wall attached to the aortic valve. Depending on the number of sinuses that had to be replaced, 1 to 3 patches were excised from the vascular graft and trimmed to teardrop shapes matching the size of the respective valve cusps. Even if the sizing is based on an eyeball judgment, the determination of the proper size of neosinuses is easier when they are cut out from the chosen vascular graft, keeping in mind that the sum of the sinuses' widths had to be equal to the circumference of the tube. Until 2006, we used a standard straight woven polyester graft ("InterGard") for the root repair, and thereafter, a special graft with an uncrimped proximal part ("InterGard Woven Aortic Thoracic Graft"; InterVascular, MAQUET Cardiovascular, La Ciotat, France) because cutting the patches from the uncrimped tube facilitates the determination of their proper size and shape and improves the tightness of the suture line by eliminating leaks between the folds of Dacron. ${ }^{10}$ In patients with a large annulus and correspondingly large, wide-opening aortic valve cusps, slightly oversized patches were trimmed from a tube that was 4 to $5 \mathrm{~mm}$ larger than the annulus. The neosinuses were plicated at their curved edges with 3 stitches, each approximately 4 to $5 \mathrm{~mm}$ wide, using 5-0 polypropylene sutures to reduce the pseudo-sinus curved edge to the proper length corresponding to the patient's annulus and, at the same time, to create a more distinct bulge. ${ }^{11}$ The patches were sewn to the rim of the aortic wall with a 5-0 polypropylene running suture passing through the aortic annulus, and in cases in which the coronary sinuses were replaced, coronary buttons were reimplanted.
In 39 patients, additional procedures on the cusps, such as cusp patch plasty (16), free margin plication (11), and decalcification or free margin shaving (11), completed the aortic root repair, if necessary. In 16 patients, an isolated cusp repair was performed comprising cusp patch plasty (10), decalcification or free margin shaving (7), and only 1 free margin plication. The techniques of cusp plasty included free margin augmentation (8), basal cusp enlargement (4), and complete replacement of a single cusp (14), and have been described in detail. ${ }^{11-13}$

Warfarin was not given postoperatively with the exception of patients with atrial fibrillation or other specific indications. Operative data including the extent of surgery are shown in Table 2.

\section{Statistical Analysis}

Informed consent was obtained from all patients, and all perioperative data were collected prospectively; however, an institutional review board approval has been waived for this study because of the retrospective and completely anonymous character of the analysis. Mortality and morbidity causes were defined and analyzed according to reporting guidelines. ${ }^{14}$ Early mortality was considered for the postoperative time of 30 and 90 days, as well as for in-hospital stay. Categoric variables are expressed in Tables 1-3 and text as frequency and continuous variables as mean \pm standard deviation (range). The patients were followed up annually in our outpatient clinic or by their cardiologists, from whom written documents and images, if available, were requested and reviewed. The last follow-up was completed within 6 months before final analysis. Actuarial survival was estimated by the Kaplan-Meier method starting with the procedure. The statistical analysis was performed with the IBM SPSS software (version 24.0; IBM Corp, Armonk, NY).

\section{RESULTS}

\section{Operative Data and Early Mortality and Morbidity}

Intraoperative, 30-day, and in-hospital-mortality were $0 \%, 2 \%$, and $3 \%$, respectively. Permanent neurologic deficit and temporary dysfunction, such as confusion, delirium, or agitation lasting more than 48 hours but without

TABLE 1. Preoperative patient characteristics

\begin{tabular}{lc}
\hline \multicolumn{1}{c}{ Characteristics } & No $=\%$ or mean \pm SD (range) \\
\hline Sex male & 44 \\
Age (y) & \\
Insufficiency grade & 23 \\
Mild & 27 \\
Moderate & 41 \\
Severe & $25.0 \pm 2.6(20-33)$ \\
Annulus diameter (mm) & $57.1 \pm 9.2(42-80)$ \\
Ascending aorta diameter* (mm) & \\
Concomitant disease & 86 \\
Hypertension & 25 \\
Coronary heart disease $\dagger$ & 9 \\
Diabetes & 5 \\
COPD & 12 \\
Previous neurologic event & 6 \\
$\quad$ With residuals & 17 \\
Acute type A dissection & 1 \\
Previous cardiac surgery & \\
\hline$S D$, Standard deviation; $C O P D$, chronic obstructive pulmonary disease (requiring \\
long-term therapy in anamnesis). ${ }^{\dagger}$ In 89 patients with increased diameter. $\dagger$ With sur- \\
gically relevant stenosis (among 91 patients in whom coronary artery visualization \\
through heart catheterization or cardiac computed tomography was performed). \\
\end{tabular}


TABLE 2. Operative data

\begin{tabular}{lc}
\hline \multicolumn{1}{c}{ Variables } & No $=\%$ or mean \pm SD (range) \\
\hline Aortic root repair & 84 \\
Additional cusp repair & 39 \\
Isolated cusp repair & 16 \\
Concomitant procedures & \\
Ascending aorta replacement & 93 \\
Total/subtotal arch replacement & 51 \\
Hemiarch replacement & 36 \\
CABG & 25 \\
Mitral valve repair & 4 \\
Aorto-carotid bypass & 1 \\
Others & 4 \\
CPB duration (min) & $156 \pm 44(46-268)$ \\
Aortic crossclamp time (min)* & $100 \pm 30(31-185)$ \\
CA of lower body (min) $\dagger$ & $24 \pm 13(9-70)$ \\
Cerebral perfusion time (min) $\dagger, \ddagger$ & $30 \pm 19(9-83)$ \\
\hline
\end{tabular}

$S D$, Standard deviation; $C A B G$, coronary artery bypass grafting; $C P B$, cardiopulmonary bypass; $C A$, circulatory arrest. *Including circulatory arrest. $\dagger$ In 87 patients with patients with arch surgery. $\ddagger$ In 67 patients, cerebral perfusion and lower body ischemia times were equal.

focal deficit, occurred in 2 patients (1 minor stroke and 1 heparin-induced thrombocytopenia-related stroke) and 6 patients, respectively.

Among the patients with stroke, 1 with acute aortic dissection (female, 77 years) had multiple embolisms after surgery caused by heparin-induced thrombocytopenia and died of multiorgan failure on postoperative day 26. Another patient (male, 79 years) with chronic atherosclerotic aneurysm and aortic valve insufficiency died suddenly on the seventh day after aortic root and complete arch repair due to malignant arrhythmia resulting in cardiac arrest after an otherwise uneventful postoperative course. At autopsy, no pathologic conditions were found apart from severe left ventricular hypertrophy.

Another patient died during the hospital stay but beyond the timeframe of 30 days because of purulent mediastinitis treated with multiple surgical revisions, including omental plasty.

Accordingly, the in-hospital mortality rates in patients with and without dissection were $5.9 \%$ and $2.4 \%$, respectively. The most frequent postoperative complication, which occurred in 53 patients, was temporary atrial fibrillation. Respiratory insufficiency necessitating prolonged ventilation or reintubation occurred in 8 patients. Six of these patients required tracheotomy.

Temporary dialysis was necessary in 5 patients. Four patients required a rethoracotomy because of bleeding; however, there were 5 further cases of pericardial effusion treated by a subxiphoid puncture.

\section{Survival}

The follow-up was $99 \%$ complete (1 patient was lost to follow-up after 20 months of uneventful course and no aortic insufficiency in last echocardiography), resulting in 427 patient/years.

During the follow-up (mean duration, $4.3 \pm 3.2$; range, 0.02-11.1 years), there were 24 late deaths (after clinic discharge) that occurred on average $50.0 \pm 40.6$ months (range, 2.4-135.0) after surgery at the average patient age of $82 \pm 5$ years (range, 75-90). Two of the deaths occurred during the 90-day period. They were caused by Clostridium difficile-associated disease and rupture of an abdominal aortic aneurysm. The causes of all late deaths are listed in Table 3. Altogether, there were 7 deaths among 17 patients with acute dissection (mean age, $80 \pm 4$ years; range, 76-88 years) and 20 deaths among the remaining patients without dissection (mean age, $77.5 \pm 2$; range, 75-83 years). Thus, the linearized death rate was $7.3 \%$ for patients with dissection and $5.0 \%$ for patients without dissection. The slightly higher mortality rate in patients with dissection can be explained by the fact that they were 2.5 years older, on average, which is a not an irrelevant aspect at the end of the eighth decade of life.

Estimated survival at 5 and 8 years was $76.4 \% \pm 5.1 \%$ and $71.3 \% \pm 5.9 \%$, respectively, and was comparable to the survival curve of an age- and sex-matched general German population provided by German Institute of Statistics - Statistisches Bundesamt (Figure 1).

\section{Valve-Related Morbidity and Reoperations}

There were 2 embolic events (strokes) in patients with atrial fibrillation at age 81 years and 84 years, and 3 bleedings, which occurred under Coumadin (2) or aspirin (1) treatment. Two bleedings were cerebral, and both were fatal. There was no case of endocarditis reported during the entire follow-up period. One patient underwent aortic valve replacement and is described next in detail.

\section{Functional Data}

The echocardiography performed during the hospital stay showed excellent valve function with no (78) or mild (22) insufficiency. The mean gradient across the aortic valve was $4.5 \pm 1.9 \mathrm{~mm} \mathrm{Hg}$.

The final echocardiographic follow-up was $86 \%$ complete, and the last available echocardiography showed $0 /$ $1+$ and $2+$ insufficiency in 90 and 9 patients, respectively. Only 1 female patient developed a relevant aortic insufficiency $(3+)$ caused by progressive restriction of nonrepaired cusps after previous coronary artery bypass grafting and aortic valve repair using basal enlargement of 1 cusp 4 years after surgery (Figure 2, Video 1) and underwent aortic valve replacement and coronary regrafting. No pathologic alterations of the aortic root were noticed during the follow-up time in any patient, and there was no relevant change of the transvalvular gradient. 
TABLE 3. Late mortality $(n=24)$

\begin{tabular}{lc}
\hline \multicolumn{1}{c}{ Cause } & No $=\%$ \\
\hline Cardiac/valve related & 6 \\
Cerebral bleeding & 2 \\
Cerebral embolism & 1 \\
Congestive heart failure & 2 \\
Myocardial infarction & 1 \\
Sudden/unknown & 1 \\
Noncardiac/nonvalve related & 17 \\
Cancer & 5 \\
Septic* & 5 \\
Senile decay & 5 \\
Aortic rupture (abdominal) & 1 \\
Lung embolism & 1 \\
\hline *Including 2 cases of pneumonia, 1 urosepsis, 1 liver abscess, and 1 Clostridium \\
difficile-associated disease.
\end{tabular}

\section{DISCUSSION}

The reimplantation technique is currently a widely used method of aortic root repair, yet it is a challenging and time-consuming procedure because it is connected with the necessity of replacing the entire root and implanting both coronary arteries, regardless of the number of pathologic sinuses. ${ }^{15}$ For this reason, even centers with the most extensive experience in the reimplantation technique do not recommend this method in risky or elder patients. ${ }^{16}$ However, the aortic aneurysms in elderly patients present mostly an arteriosclerotic etiology, in which an unequal dilatation of particular sinuses of Valsalva is characteristic. Accordingly, only $18 \%$ of our patients with aortic root repair needed a replacement of all 3 sinuses. On the other hand, they are exactly the cusps that are the main subject of alteration during the process of valve aging. In a longterm observation reported by David and colleagues ${ }^{17}$ in 2010 , it could be demonstrated that the patient's age was the only predictor of recurrent aortic insufficiency after a valve-sparing root repair (VSRR) regardless of whether remodeling or reimplantation was performed. ${ }^{17}$ Therefore, cusp procedures are more frequently necessary for repairing the insufficient aortic valve in the elderly than isolated VSRRs. In our cohort, only $45 \%$ of patients could be treated using isolated VSRR, but it would have been approximately $30 \%$ if the patients with acute dissection were excluded from evaluation.

Given that cusp pathology is most frequently present in elderly patients with aortic insufficiency, the isolated sinus repair with single patches offers additional advantages when the root also has to be approached. By leaving the unchanged sinuses in place, valuable time can be saved for cusp procedures, and, most important, an evaluation of the valve and all necessary cusp repairs is easier to perform because the valve is not located deep inside the tube.

In general, the patient suitability and surgeon availability are major limitations of aortic valve repair. Yet, it affects not only the elderly patients. Tirone David, one of the pioneers of reconstructive aortic valve surgery wrote in one of his articles ..." they (VSRRs) are demanding operations and only surgeons with extensive experience in aortic surgery should perform them." ${ }^{18}$ It is increasingly recognized that complex aortic valve or root repairs comprise challenging and timeconsuming procedures and should be performed by experienced surgeons in selected patients, because surgeon experience is one of the most important factors affecting repair outcomes, such as the functional results and longterm durability. ${ }^{19,20}$ Accordingly, we are frequently asked about the role of surgical experience and, especially, about reproducibility of the techniques used, but we do not consider the surgical skills or reproducibility as a decisive factor. A recent evaluation of surgical results obtained in several centers after VSRR, performed mainly using the reimplantation technique (widely considered as
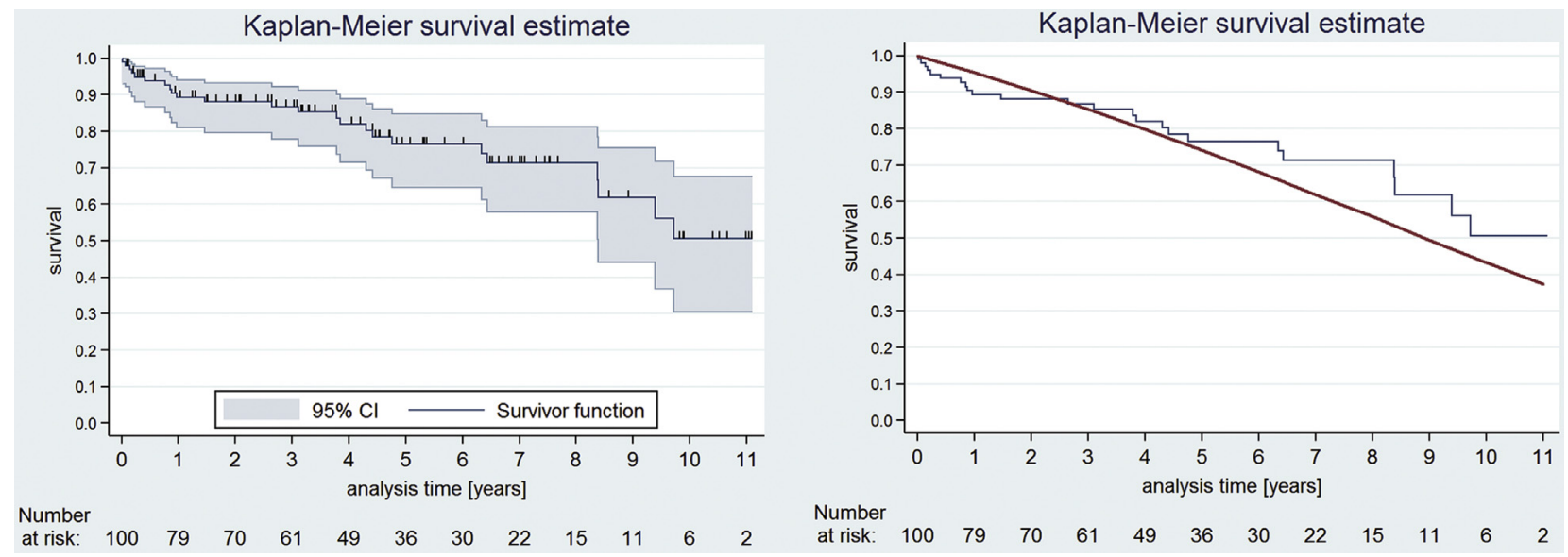

FIGURE 1. Left: Actuarial survival (Kaplan-Meier) after aortic valve/root repair. Survival was calculated starting with the procedure. Right: Comparison of estimated survival after aortic valve/root repair (black line) versus aged- and sex-matched German population (red line). 

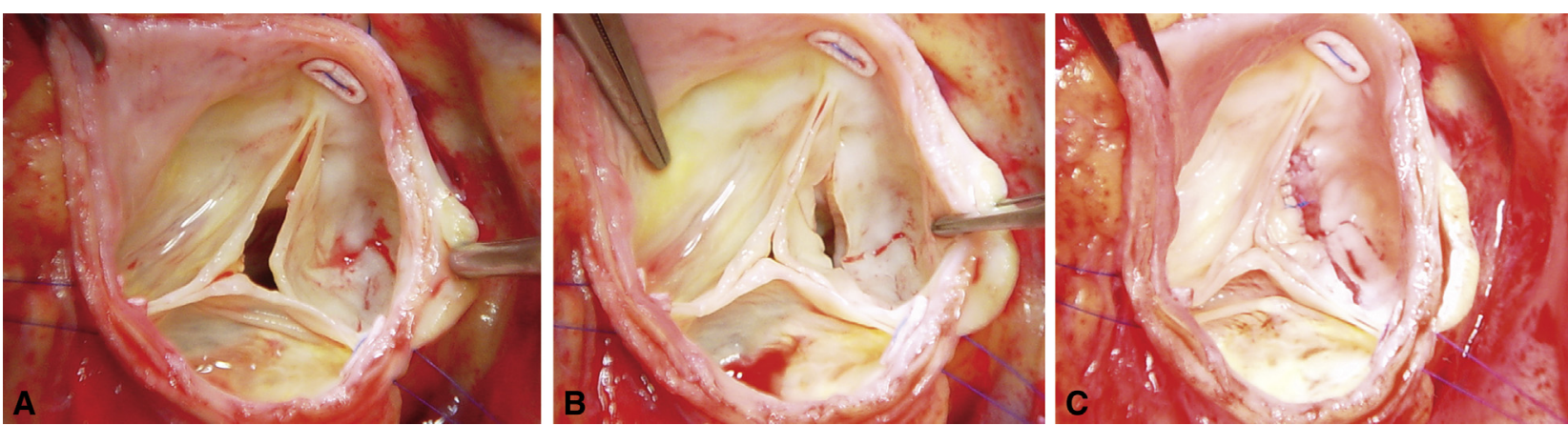

FIGURE 2. Intraoperative photographs demonstrating failed coaptation as the result of noncoronary cusp restriction (A), basal cusp incision and consecutive centripetal movement (B), and normalization of cusp size after closing the incision with oval pericardial patch (C).

well reproducible), revealed that there is no panacea for successful aortic root repair. Even if $52 \%$ of the patients had no insufficiency before surgery, a $29 \%$ rate of any aortic regurgitation was observed after leaving the operating room. Moreover, the freedom of aortic valve reoperation at 8 years was $89 \%$ in patients with any degree of preoperative aortic insufficiency, but only $84 \%$ in those with no preoperative insufficiency at all. ${ }^{20}$ Therefore, we are convinced that, corresponding to the Albert Einstein citation, "the formulation of a problem is more important than the formulation of the solution because the definition of the problem leads to the solution." ${ }^{21}$ Thus, the understanding of pathophysiology, for which a lot of individual experience is necessary, is, in our opinion, decisive for recognition of the true cause of aortic insufficiency and the subsequent application of suitable techniques. This is probably a reason why an exceptional expertise of highvolume centers is mostly based on the individual experience of particular surgeons. In the elderly, the aspect of surgical experience seems to play even more of a role. The surgeons

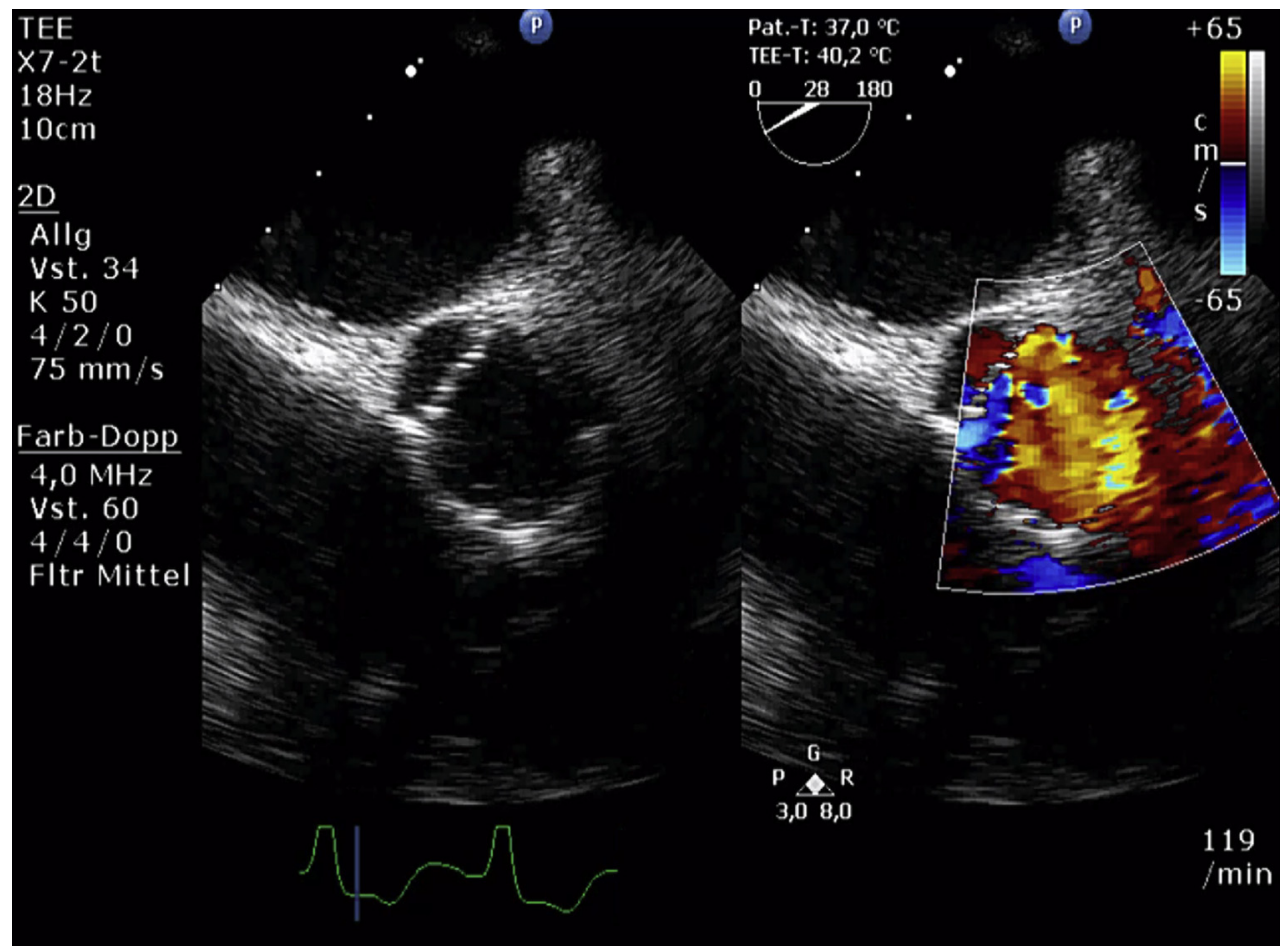

VIDEO 1. Transesophageal echocardiography (TEE) demonstrating development of relevant aortic insufficiency after repair caused by cusp restriction. "Before Repair" TEE, short and long axis without and with color flow Doppler before repair. "After Repair" TEE, short and long axis after repair showing good coaptation with trace residual insufficiency after repair consisting of basal cusp enlargement (intraoperative photographs of the same patient are presented in Figure 2), and "4 Years after Repair" TEE, short and long axis showing relevant recurrent insufficiency caused by progressive cusp restriction 4 years after primary surgery. Video available at: http://www.jtcvsonline.org/article/S0022-5223(17)32896-9/fulltext. 
have to be quite sure about the primary surgical and functional results because any corrections are connected with a second run and prolonged operative times (ischemia, cardiopulmonary bypass), which are not tolerated as well as by younger patients. Admittedly, also in this cohort, the majority of surgeries (93) were performed by the senior author (PPU), even if 4 further surgeons are skilled in the described root repair technique, which is used in our center exclusively.

The current generation of biological prostheses offer durability that generally exceeds the life expectancy in elderly patients and so should the outcomes of valve repair. Admittedly, a durable $100 \%$ repair success is hardly possible, and it was not achieved in our population because 1 patient needed aortic valve replacement during the followup period. However, valve replacement also does not mean a $100 \%$ rate of durable success because there are still cases of early deterioration or paravalvular leakage, which can occur after replacement surgery. ${ }^{22,23}$

Yet, even if a biological valve replacement is a surgical standard in elderly patients, the age alone is not a criterion to refuse reconstructive surgery. On the contrary, avoiding implantation of an artificial valve is particularly advantageous in elderly patients because the risk of endocarditis (which was not observed in any patient of our entire group) increases with advanced age. ${ }^{24}$ The same regards an incidence of other valve-related events, which was very low in our study population. The linearized rate of embolism was approximately $0.5 \% / y e a r$, and the rate of bleeding was $0.7 \%$. However, all these events were not strictly associated with the previous aortic valve repair. Both patients with stroke had had atrial fibrillation, and all bleeding episodes were connected to antithrombotic therapy, which was not specifically indicated by the aortic surgery.

\section{Study Limitations}

The lack of randomization and patient selection, which may have introduced a selection bias, can be considered a limitation of the study. However, the group contains all consecutive patients who underwent reconstructive aortic valve or root surgery, and all relevant perioperative parameters were collected prospectively. We are even convinced that the variety of aortic pathologies, clinical parameters, and surgeon experience demand individual therapy, which is essential for optimal outcome; therefore, a randomization would not have been justified in such patients. Furthermore, the follow-up echocardiographs were performed in most patients by their cardiologists, who generally used a 5 -grade scale $(0-4+)$ of aortic insufficiency; therefore, any changes between trivial and mild insufficiency could not be determined; however, those changes are neither clinically nor functionally relevant, and there was only 1 patient in whom a significant insufficiency developed, which was treated with a valve replacement.

\section{CONCLUSIONS}

On the basis of the data presented, we conclude that reconstructive aortic valve surgery is a suitable and justifiable surgical option in selected elderly patients undergoing operation by surgeons who have considerable experience with this kind of surgery. As demonstrated in our cohort, it offers low cardiac as well as low valve-related mortality and morbidity, leading to life expectancy applicable to the patients' ages.

\section{Conflict of Interest Statement}

P.P.U. is a consultant for and has a financial relationship with MAQUET Cardiovascular, Inc. All other authors have nothing to disclose with regard to commercial support.

The authors thank Melissa Lindner for assistance in preparing this article.

\section{References}

1. Svenson LG, Adams DH, Bonow RO, Kouchoukos NT, Miller DC, O'Gara PT, et al. Aortic valve and ascending aorta guidelines for management and quality measures: executive summary. Ann Thorac Surg. 2013;95:1491-505.

2. Edwards FH, Peterson ED, Coombs LP, DeLong ER, Jamieson WRE Shroyer ALW, et al. Prediction of operative mortality after valve replacement surgery. J Am Coll Cardiol. 2001;37:885-92.

3. Okamoto Y, Yamamoto K, Yoshii S. Early and late outcomes of aortic valve replacement using bioprosthetic versus mechanical valve in elderly patients: a propensity analysis. J Card Surg. 2016;31:195-202.

4. Aydin E, Yerlikhan OA, Tuzun B, Ozen Y, Sarikaya S, Kirali MK. How to approach aortic valve disease in the elderly: a 25-year retrospective study. Cardiovasc J Afr. 2014;25:244-8

5. Gilmanov D, Farneti PA, Ferrarini M, Santarelli F, Murzi M, Miceli A, et al. Full sternotomy versus right anterior minithoracotomy for isolated aortic valve replacement in octogenarians: a propensity-matched study. Interact Cardiovasc Thorac Surg. 2015;20:732-41.

6. Fok M, Shaw M, Sancho E, Abello D, Bashir M. Aortic valve repair: a systematic review and meta-analysis of published literature. Aorta. 2014;2:10-21.

7. Bashir M, Oo A, De Paulis R, Borger MA, El Khoury G, Bavaria J, et al. Can the results of aortic valve repair equal the results of a biologic aortic valve replacement? Aorta. 2014;2:1-9.

8. Lancellotti P, Tribouilloy C, Hagendorff A, Moura L, Popescu BA, Agricola E, et al. European association of echocardiography recommendations for the assessment of valvular regurgitation. Part 1: aortic and pulmonary regurgitation (native valve disease). Eur J Echocardiogr. 2010;11:223-44.

9. Urbanski PP. Valve-sparing aortic root repair with patch technique. Ann Thorac Surg. 2005;80:839-44.

10. Urbanski PP, Zhan X, Frank S, Diegeler A. Aortic root reconstruction using new vascular graft. Interact Cardiovasc Thorac Surg. 2009;8:187-90.

11. Urbanski PP, Jankulowski A, Morka A, Irimie V, Zhan X, Zacher M, et al. Patient-tailored aortic root repair in adult marfanoid patients: surgical considerations and outcomes. J Thorac Cardiovasc Surg. 2018;155:43-51.e1.

12. Urbanski PP. Basal cusp enlargement for repair of aortic valve insufficiency. $J$ Thorac Cardiovasc Surg. 2010;139:98-102.

13. Urbanski PP. Aortic valve insufficiency with extensive cusp pathology: repair with a pericardial patch. Eur J Cardiothorac Surg. 2010;37:962-4.

14. Akins CW, Miller DC, Turina MI, Kouchoukos NT, Blackstone EH Grunkemeier GL, et al. Guidelines for reporting mortality and morbidity after cardiac valve interventions. Ann Thorac Surg. 2008;85:1490-5.

15. David TE, David CM, Feindel CM, Manlhiot C. Reimplantation of the aortic valve at 20 years. J Thorac Cardiovasc Surg. 2017;153:232-8.

16. Shrestha M, Baraki H, Maeding I, Fitzner S, Sarikouch S, Khaladj N, et al. Longterm results after aortic valve-sparing operation (David I). Eur J Cardiothorac Surg. 2012;41:56-62.

17. David TE, Maganti M, Armstrong S. Aortic root aneurysm: principles of repair and long-term follow-up. J Thorac Cardiovasc Surg. 2010;140:14-9. 
18. David TE. Long-term results of aortic valve-sparing operations for aortic root aneurysm. J Thorac Cardiovasc Surg. 2006;132:347-54.

19. Lenos A, Bougioukakis P, Irimie V, Zacher M, Diegeler A, Urbanski PP. Impact of surgical experience on outcome in surgery of acute type A aortic dissection. Eur J Cardiothorac Surg. 2015;48:491-6.

20. Kari FA, Doll KN, Hemmer W, Liebrich M, Sievers HH, Richardt D, et al. Residual and progressive aortic regurgitation after valve-sparing root replacement: a propensity-matched multi-institutional analysis in 764 patients. Ann Thorac Surg. 2016;101:1500-6.

21. Einstein A, Infeld L. The decline of the mechanical view. In: Snow CP, ed. The Evolution of Physics. Cambridge, UK: Cambridge University Press; 1938:92.
22. Alvarez JR, Sierra J, Vega M, Adrio B, Martinez-Comendador J, Gude F, et al Early calcification of the aortic Mitroflow pericardial bioprosthesis in the elderly. Interact Cardiovasc Thorac Surg. 2009;9:842-6.

23. Ionescu A, Fraser AG, Butchart EG. Prevalence and clinical significance of incidental paraprosthetic valvar regurgitation: a prospective study using transoesophageal echocardiography. Heart. 2003;89:1316-21.

24. Remadi JP, Nadji G, Goissen T, Zomvuama NA, Sorel C, Tribouilloy C. Infective endocarditis in elderly patients: clinical characteristics and outcome. Eur J Cardiothorac Surg. 2009;35:123-9.

Key Words: aortic valve, aortic root, surgery, valve repair

Readers who found these articles interesting may also like to read the following papers found in recent and future issues of our sister publications, Seminars in Thoracic and Cardiovascular Surgery and Operative Techniques in Thoracic and Cardiovascular Surgery!

Adult: Aortic Valve

STATE OF THE ART: Aortic Valve Replacement: Are We Spoiled for Choice? Mohamad Bashir. Semin Thoracic Surg $2017: 265-272$.

STATE OF THE ART: Sutureless Sorin Perceval Aortic Valve Implantation. Steffen Pfeiffer. Semin Thoracic Surg $2017:$ 1-7.

ORIGINAL SUBMISSION: Single-dose del Nido Cardioplegia in Minimally Invasive Aortic Valve Surgery. Daniel Ziazadeh. Semin Thoracic Surg 2017: 471-476.

Editorial Commentary: Is “As Good” Good Enough? James I. Fann. Semin Thoracic Surg 2017: 477-478.

ORIGINAL SUBMISSION: Aortic Valve Replacement Using a Perceval Sutureless Aortic Bioprosthesis. David Heimansohn. Oper Tech Thorac Cardiovasc 2017: 282-305.

ORIGINAL SUBMISSION: Intuity Elite Valve Implantation Technique. Kyle W. Eudailey. Oper Tech Thorac Cardiovasc 2017: 306-321.

ORIGINAL SUBMISSION: How to Perform a Simplified Technique for Transapical Aortic Valve Implantations. Pierre-Yves Litzler. Oper Tech Thorac Cardiovasc 2016: 89-111.

ORIGINAL SUBMISSION: Comparison of Aortic Annulus Dimension after Aortic Valve neocuspidization with valve replacement and normal valve. Yoshitaka Yamamoto. Semin Thoracic Surg 2017: 143-149. 